\title{
Potential predictors for chemotherapeutic response and prognosis in epithelial ovarian, fallopian tube and primary peritoneal cancer patients treated with platinum-based chemotherapy
}

\author{
Dhammapoj Jeerakornpassawat, MD, Prapaporn Suprasert, MD \\ Division of Gynecologic Oncology, Department of Obstetrics and Gynecology, Faculty of Medicine, Chiang Mai University, Chiang Mai, Thailand
}

\section{Objective}

This study aimed to investigate the potential predictive factors for platinum resistance and poor prognosis in epithelial ovarian, fallopian tube, and primary peritoneal cancer treated with platinum-based chemotherapy.

\section{Methods}

Medical records of 306 patients with the above mentioned cancers treated with platinum-based chemotherapy between 2007 and 2017 were retrospective reviewed. Clinical data, preoperative neutrophil-to-lymphocyte ratio (NLR), platelet-to-lymphocyte ratio (PLR), platinum-free interval, and survival time were recorded. NLR, PLR, and cancer antigen 125 (CA125) levels were calculated for an optimal cutoff point using receiver operating characteristic curves. The clinicopathological variables were compared using univariate and multivariate analyses to identify independent predictive factors for platinum resistance and poor survival outcomes.

Results

The optimal cutoff points for NLR, PLR, and CA125 were 3.38, 210, and $365 \mathrm{IU} / \mathrm{L}$, respectively. Univariate analysis indicated that NLR $>3.38$, PLR $>210$, CA125 $\geq 365$, advanced stage, suboptimal disease, serous type, and ascites were significant predictive factors for platinum resistance. However, only NLR $>3.38$ and advanced stage were independent predictive factors with an adjusted odds ratio of 1.880 and 3.333, respectively. Regarding factors associated with poor survival outcomes, only PLR >210 and advanced stage were independent factors, with a hazard ratio of 1.578 and 3.994 , respectively.

Conclusion

High NLR and advanced stage were potential independent predictive factors for platinum resistance, whereas high PLR and advanced stage were potential independent predictive factors for poor survival outcomes.

Keywords: Neutrophil; Lymphocyte; Platelet; Ovarian cancer; Platinum

\section{Introduction}

Ovarian cancer is ranked as the $8^{\text {th }}$ most common cancer among women worldwide, with an age-standardized incidence rate of 6.6. Epithelial ovarian cancer (EOC) accounts for over $90 \%$ of all ovarian cancers [1]. Since there is no effective screening test for EOC, over $75 \%$ of the patients in the sample were diagnosed with cancer at an advanced stage, resulting in poor outcomes. The standard treatment consists of surgery followed by platinum-based chemo-
Received: 2019.05.30. Revised: 2019.08.16. Accepted: 2019.08.25. Corresponding author: Prapaporn Suprasert, MD Division of Gynecologic Oncology, Department of Obstetrics and Gynecology, Faculty of Medicine, Chiang Mai University, 110 Intavaroros Road, Chiang Mai 50200, Thailand E mail: psuprase@gmail.com https://orcid.org/0000-0002-0205-2280

Articles published in Obstet Gynecol Sci are open-access, distributed under the terms of the Creative Commons Attribution Non-Commercial License (http://creativecommons. org/licenses/by-nc/3.0/) which permits unrestricted non-commercial use, distribution, and reproduction in any medium, provided the original work is properly cited.

Copyright $\odot 2020$ Korean Society of Obstetrics and Gynecology 


\section{Obstetrics \& Gynecology Science}

Vol. 63, No. 1, 2020

therapy, usually administered in 6 cycles of carboplatin and paclitaxel (PT) with or without bevacizumab. However, the median progression-free interval, especially in the advanced stages of cancer, was about 18 months, with approximately $80 \%$ of patients having a recurrence within $1-2$ years [2].

In addition, patients with tumor progression over 6 months after completing treatment with platinum-based chemotherapy could be benefit from retreatment with the platinumbased regimen again and were categorized as platinumsensitive patients. In contrast to patients whose tumor progression during or under 6 months after completing treatment showed very poor prognoses and were categorized as platinum-resistant patients due to no benefit from platinum-based chemotherapy [3]. Considering these findings, it is imperative to discover potential predictive factors that identify patients who are resistant to platinum-based treatment and at a high risk of early progression. If identified earlier, platinum-resistant EOC patients could benefit from aggressive therapeutic schedules in the first-line treatment, such as extensive surgical debulking procedure, use of dose-dense chemotherapy, or addition of a targeted therapy (e.g., bevacizumab).

A recent molecular cancer study suggested that an increase in the parameters of inflammatory markers, such as neutrophils and platelets, could facilitate tumor initiation, tumor progression, induction of angiogenesis, and promote metastatic spreading by inhibiting the natural killer functions of the body [4]. Thus, the elevated neutrophil-to-lymphocyte ratios (NLRs) and platelet-to-lymphocyte ratios (PLRs) in many solid tumors can be associated with worse prognoses [5]. In addition, other clinical manifestations such as the presence of malignant ascites, a suboptimal residual tumor, a high cancer antigen 125 (CA125) reading and a high-grade tumor can also be related to poorer outcomes [5-7]. However, studies to predict the factors involved in platinum-based chemotherapeutic responses are still limited. This study was conducted as a retrospective review to identify the potential clinical and blood inflammatory parameters that could be used to predict platinum status and survival outcomes in patients with EOC.

\section{Materials and methods}

\section{Patient selection}

This retrospective study was conducted following the ap- proval by the Research Ethics Committee at Chiang Mai University Hospital. The medical records of patients with EOC, fallopian tube cancer and primary peritoneal adenocarcinoma who were initially treated through either primary surgery or neoadjuvant chemotherapy before surgery at the Chiang Mai University Hospital, between January 2007 and December 2017, were retrospective reviewed. Patients with missing data were excluded. Finally, 306 patients who met the inclusion criteria were recruited into the study. The following clinical and pathological data were collected: age, body mass index, parity, menopausal status, the presence of ascites, primary treatment, International Federation of Gynecology and Obstetrics (FIGO) staging, residual disease, estimated blood loss during surgery, operative time, histology, and tumor grade. All patients enrolled in the study underwent comprehensive surgical staging or tumor debulking as clinically indicated. Optimal debulking was defined as a procedure that left a maximum residual tumor of less than $1 \mathrm{~cm}$. The chemotherapy regimens consisted of carboplatin area under the curve (AUC) $=5$ plus paclitaxel $175 \mathrm{mg} / \mathrm{m}^{2}$ (PT regimen) or single carboplatin AUC 5-6. All regimens were given every 3 weeks for a total of 6 cycles. If disease progression or severe toxicity occurred, chemotherapy was discontinued. In addition, some patients continued on a chemotherapy regimen beyond 6 cycles if deemed necessary by their physicians. Neoadjuvant chemotherapy was administered when debulking surgery was not suitable for the patient.

Blood tests for ovarian cancer antigen (CA125) and hematologic markers were collected within 3 weeks prior to initial treatment. NLR and PLR were calculated from complete blood cell count using the absolute neutrophil count divided by the absolute lymphocyte count and the absolute platelet count divided by the absolute lymphocyte count, respectively.

After treatment was completed, the patients' response to therapy was evaluated using radiologic evaluation and/ or CA125 measurement. Follow up included a physical examination and a CA125 blood test every 3 months in the $1^{\text {st }}$ year, every 4 months in the $2^{\text {nd }}$ year, every 6 months in the $3^{\text {rd }}$ to $5^{\text {th }}$ years, and subsequently annually. The diagnosis of progression was determined according to the Response Evaluation Criteria in Solid Tumors or tumor markers.

Patients were divided into 2 groups according to the time to progression after chemotherapy was discontinued. The first group was defined as the platinum-resistant group as patients developed tumor progression during or within 


\section{Obstetrics \& Gynecology Science}

Dhammapoj Jeerakornpassawat, et al. Potential factors for ovarian cancer

Table 1. Patient characteristics $(n=306)$

\begin{tabular}{|c|c|}
\hline Characteristics & Value \\
\hline Mean age (years) & $54.14 \pm 9.72$ \\
\hline Mean BMI $\left(k g / m^{2}\right)$ & $22.95 \pm 3.78$ \\
\hline Median CA125 (range: 8.5-40,340) & 373.5 \\
\hline \multicolumn{2}{|l|}{ Hematologic parameters (range) } \\
\hline Hemoglobin (7.6-15.0; gm\%) & $11.46(11.5)$ \\
\hline WBC $(3,860-30,500 ;$ cu.mm.) & $8,848(7,935)$ \\
\hline ANC $(1,599.6-26,901.0 ;$ cu.mm.) & $6,362.7(5,341.0)$ \\
\hline Platelet (79,000-909,000; cu.mm.) & $369,685(335,000)$ \\
\hline NLR (0.64-30.75) & $4.3(3.4)$ \\
\hline PLR (42.54-1,078.90) & $245.5(209.9)$ \\
\hline $\begin{array}{l}\text { Mean estimated blood loss } \\
\text { (median: } 400 \text {, range: } 50-5,000 ; \mathrm{mL} \text { ) }\end{array}$ & $660 \pm 674.59$ \\
\hline Mean operative time (minutes) & $174.93 \pm 59.83$ \\
\hline Menopause & $196(64.1)$ \\
\hline Nulliparity & $105(34.3)$ \\
\hline Epithelial ovarian cancer & $249(81.4)$ \\
\hline Fallopian tube cancer & $35(11.4)$ \\
\hline Primary peritoneal cancer & $22(7.2)$ \\
\hline \multicolumn{2}{|l|}{ FIGO stage } \\
\hline I & $92(30.1)$ \\
\hline$\|$ & $22(7.19)$ \\
\hline III & $129(42.2)$ \\
\hline IV & $18(5.9)$ \\
\hline \multicolumn{2}{|l|}{ Surgical outcome } \\
\hline No residual tumor & $151(49.3)$ \\
\hline Optimal status (residual tumor $\geq 1 \mathrm{~cm}$ ) & $54(17.6)$ \\
\hline Suboptimal status (residual tumor $>1 \mathrm{~cm}$ ) & $101(33.0)$ \\
\hline \multicolumn{2}{|l|}{ Histology } \\
\hline Serous & $126(41.2)$ \\
\hline Mucinous & $19(6.2)$ \\
\hline Endometrioid & $38(12.4)$ \\
\hline Clear cell & $80(26.1)$ \\
\hline Mixed & $33(10.8)$ \\
\hline Adenocarcinoma & $9(2.9)$ \\
\hline Transitional cell carcinoma & $1(0.3)$ \\
\hline \multicolumn{2}{|l|}{ Primary treatment } \\
\hline Neoadjuvant chemotherapy & $75(24.5)$ \\
\hline Carboplatin plus paclitaxel & $69(22.5)$ \\
\hline Carboplatin & $6(2.0)$ \\
\hline \multicolumn{2}{|l|}{ Cycle of neoadjuvant chemotherapy } \\
\hline 1 & 7 \\
\hline 2 & 9 \\
\hline
\end{tabular}

Table 1. Continued.

\begin{tabular}{|c|c|}
\hline Characteristics & Value \\
\hline 3 & 39 \\
\hline 4 & 10 \\
\hline 5 & 2 \\
\hline 6 & 8 \\
\hline Upfront surgery & $231(75.5)$ \\
\hline Adjuvant chemotherapy & 305 \\
\hline Carboplatin plus paclitaxel & $283(92.8)$ \\
\hline Single carboplatin & $22(7.2)$ \\
\hline \multicolumn{2}{|l|}{ No. of adjuvant chemotherapy } \\
\hline 1 & 3 \\
\hline 2 & 9 \\
\hline 3 & 43 \\
\hline 4 & 18 \\
\hline 5 & 9 \\
\hline 6 & 213 \\
\hline 7 & 4 \\
\hline 8 & 2 \\
\hline 9 & 3 \\
\hline 10 & 1 \\
\hline \multicolumn{2}{|l|}{ Platinum status } \\
\hline Resistant & $118(38.6)$ \\
\hline Sensitive & $188(61.4)$ \\
\hline \multicolumn{2}{|l|}{ Final status } \\
\hline Death & $146(47.7)$ \\
\hline
\end{tabular}

Values are presented as mean \pm standard deviation, number (\%) or mean (median).

BMI, body mass index; CA125, cancer antigen 125; WBC, white blood cell; ANC, absolute neutrophil count; NLR, neutrophil-to-lymphocyte ratio; PLR, platelet-to-lymphocyte ratio; FIGO, International Federation of Gynecology and Obstetrics.

6 months of completion of chemotherapy. The second group was defined as the platinum-sensitive group as tumor progression occurred at 6 months or longer after completion of treatment.

Overall survival was defined as the time from treatment initiation to the last follow up or death.

\section{Statistical analysis}

Statistical analysis was performed using the IBM SPSS Statistics for Windows program (version 22; IBM Corp., Armonk, NY, USA). Chi-square or Fisher's exact test were used for the comparative analysis of the factors between the platinum- 


\section{Obstetrics \& Gynecology Science}

Vol. 63, No. 1, 2020

resistant and -sensitive groups and to calculate odds ratios (ORs) for the categorical variables. They were also used for comparative clinical variables between both cut-point NLR and PLR. A receiver operating characteristic (ROC) curve was used to assess the discriminative role of the NLR, PLR, and CA125 levels, and the best cutoff value for each item was determined to further predict the platinum status. Binary logistic regression analysis with a backward likelihood ratio method was used to identify the potential independent predictive factors for platinum resistance. The cumulative survival curve was estimated using the Kaplan-Meier method. A comparison between survival curves for each factor was carried out using the log rank test for the analysis of equality of survival distribution. Cox proportional hazard models were applied to explore predictors of survival outcomes through univariate and multivariate analyses. A $P$-value of $<0.05$ was considered statistically significant.

\section{Results}

The patient characteristics are noted in Table 1 . Over $80 \%$ of

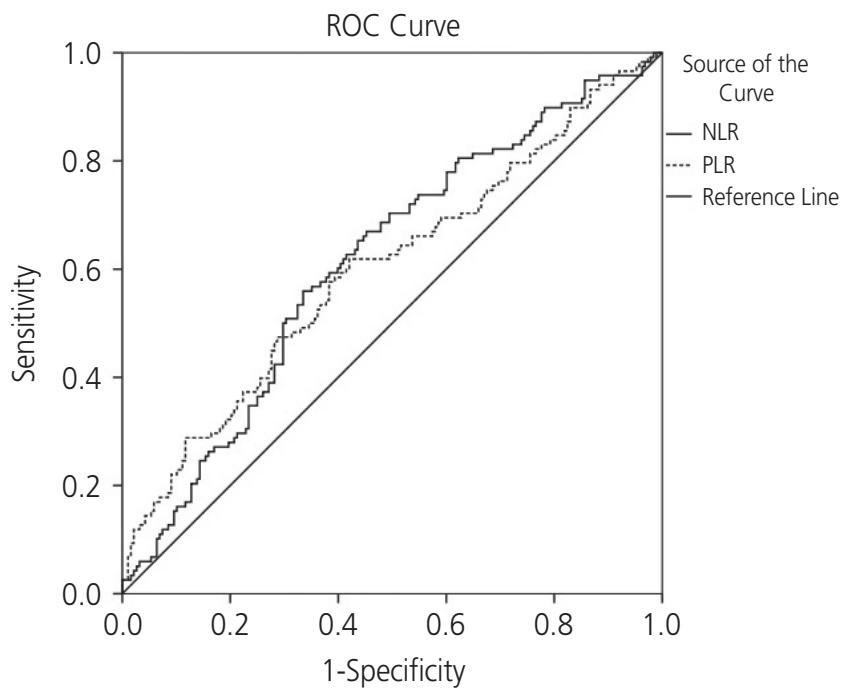

\begin{tabular}{lcccccc}
\hline Test & AUC & $\mathbf{9 5 \%} \mathrm{Cl}$ & $\begin{array}{c}\text { Cutoff } \\
\text { point }\end{array}$ & $\begin{array}{c}\text { Sensi- } \\
\text { tivity }\end{array}$ & $\begin{array}{c}\text { Speci- } \\
\text { ficity }\end{array}$ & $\boldsymbol{P}$-value \\
\hline NLR & 0.614 & $0.550-0.679$ & 3.38 & 0.619 & 0.585 & 0.001 \\
PLR & 0.600 & $0.533-0.666$ & 210 & 0.619 & 0.580 & 0.003 \\
\hline
\end{tabular}

Fig. 1. ROC and AUC for hematologic parameters to predict platinum status. NLR, neutrophil-to-lymphocyte ratio; PLR, platelettolymphocyte ratio; $\mathrm{Cl}$, confidence interval; $\mathrm{ROC}$, receiver operating characteristic; AUC, area under the curve. patients were diagnosed with EOC and half of them had advanced-stage cancer. Neoadjuvant chemotherapy was administered in $24.5 \%$ of the patients, with the primary regimen being carboplatin plus paclitaxel (PT). Most patients received 3 cycles. The surgery achieved no residual disease and optimal status in $49.3 \%$ and $17.6 \%$ of cases, respectively. Approximately $41.2 \%$ of the patients' histology revealed serous cystadenocarcinoma. Over $90 \%$ of the studied patients received adjuvant chemotherapy with PT regimen, whereas the remaining patients received single carboplatin. One patient did not receive adjuvant chemotherapy because she received 6 cycles of PT regimen in the neoadjuvant chemotherapy setting; the final histology from surgery revealed no malignancy. Majority of the studied patients were given 6 cycles of adjuvant chemotherapy with maximum number 10 cycles in 1 patient who received 4 cycles of PT regimen before developing transaminitis. This patient's chemotherapy regimen was changed to carboplatin for a further 6 cycles.

Platinum resistance was found in approximately $40 \%$ of the patients. To identify the potential predictive factors of

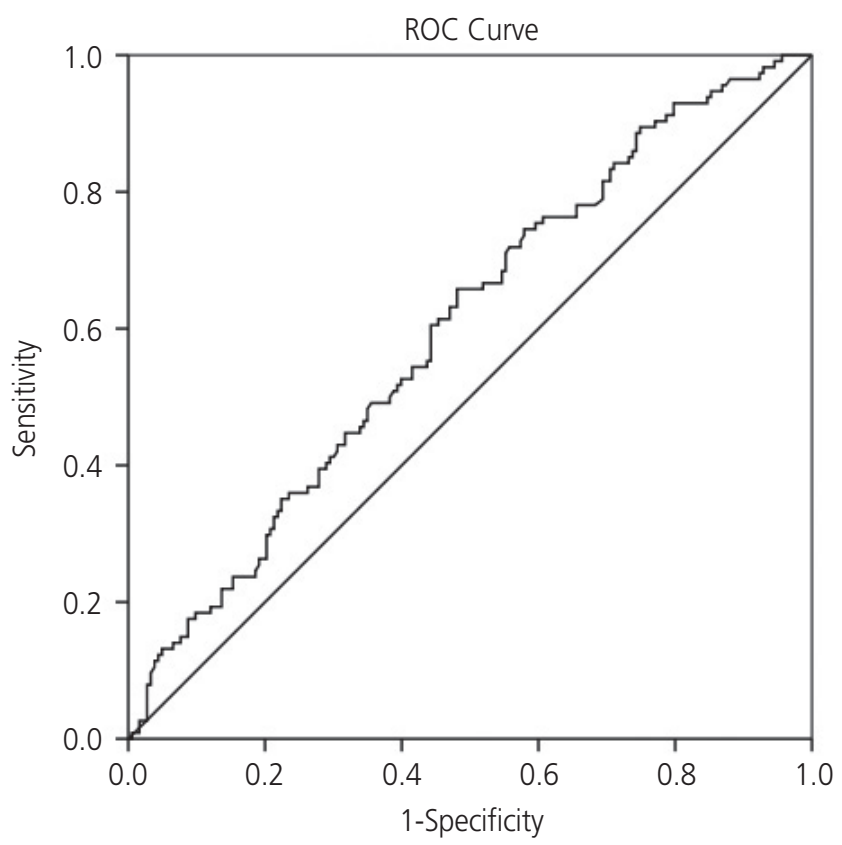

Diagonal segments are produced by ties.

\begin{tabular}{lcccccc}
\hline Test & AUC & $\mathbf{9 5 \%}$ Cl & $\begin{array}{c}\text { Cutoff } \\
\text { point }\end{array}$ & $\begin{array}{c}\text { Sensi- } \\
\text { tivity }\end{array}$ & $\begin{array}{c}\text { Speci- } \\
\text { ficity }\end{array}$ & P-value \\
\hline CA125 & 0.602 & $0.536-0.667$ & 365 & 0.600 & 0.560 & 0.003 \\
\hline
\end{tabular}

Fig. 2. ROC and AUC for CA125 level to predict platinum status. CA125, cancer antigen 125; Cl, confidence interval; ROC, receiver operating characteristic; AUC, area under the curve. 


\section{Obstetrics \& Gynecology Science}

Dhammapoj Jeerakornpassawat, et al. Potential factors for ovarian cancer

platinum resistance, $R O C$ and the $A U C$ for the optimum cutoff points of NLR, PLR, and CA125 were used, and the results showed the most effective cutoff point were 3.38 for NLR, 210 for PLR, and 365 IU/L for CA125 (Figs. 1 and 2).

The possible risk factors for predicting platinum resistance were categorized into 2 groups for comparison in the univariate analysis, and the significant factors were further evaluated in the multivariate analysis as noted in Table 2 . The results showed the risk factor NLR to be $>3.38$, PLR to be $>210$, and
CA125 levels to be $\geq 365 \mathrm{IU} / \mathrm{L}$. Advanced stage, suboptimal disease, serous type and the presence of ascites were significant potential predictive factors for platinum resistance. However, only an NLR >3.38 and advanced stage were independent potential predictive factors for platinum resistance with the adjusted ORs of 1.880 and 3.333, respectively.

Regarding prognostic factors related to survival outcomes, an NLR >3.38, a PLR >210, a CA125 $\geq 365$ IU/L, advanced stage, suboptimal diseases, serous histology, tumor grade

Table 2. Factors to predict platinum status

\begin{tabular}{|c|c|c|c|c|c|c|c|}
\hline \multirow{2}{*}{ Factors } & \multicolumn{2}{|c|}{$\begin{array}{l}\text { No. of patients divided by } \\
\text { platinum status }\end{array}$} & \multirow{2}{*}{ Total } & \multicolumn{2}{|c|}{ Univariate analysis $^{\mathrm{a})}$} & \multicolumn{2}{|c|}{ Multivariate analysis ${ }^{\text {b) }}$} \\
\hline & $\begin{array}{l}\text { Resistant } \\
(\%)\end{array}$ & $\begin{array}{l}\text { Sensitive } \\
(\%)\end{array}$ & & OR $(95 \% \mathrm{Cl})$ & $P$-value & $\begin{array}{l}\text { Adjusted OR } \\
(95 \% \mathrm{Cl})\end{array}$ & $P$-value \\
\hline \multicolumn{8}{|l|}{ NLR } \\
\hline$>3.38$ & $74(24.2)$ & $78(25.5)$ & 152 & $2.372(1.478-3.805)$ & $<0.001$ & $1.880(1.144-3.090)$ & 0.013 \\
\hline$\leq 3.38$ & $44(14.4)$ & $110(35.9)$ & 154 & & & & \\
\hline \multicolumn{8}{|l|}{ PLR } \\
\hline$>210$ & $73(23.9)$ & $80(26.1)$ & 153 & $2.190(1.368-3.507)$ & 0.001 & $1.368(0.792-2.365)$ & 0.261 \\
\hline$\leq 210$ & $45(14.7)$ & $108(35.3)$ & 153 & & & & \\
\hline \multicolumn{8}{|l|}{ CA125 level (IU/L) } \\
\hline$\geq 365$ & $69(22.5)$ & $81(26.5)$ & 150 & $1.860(1.167-2.965)$ & 0.009 & $0.992(0.553-1.780)$ & 0.978 \\
\hline$<365$ & $49(16.0)$ & $107(35.0)$ & 156 & & & & \\
\hline \multicolumn{8}{|l|}{ Parity } \\
\hline Nulliparity & $39(12.7)$ & $66(21.6)$ & 105 & $0.913(0.561-1.485)$ & 0.712 & $1.153(0.676-1.968)$ & 0.602 \\
\hline Multiparity & $79(25.8)$ & $122(39.9)$ & 201 & & & & \\
\hline \multicolumn{8}{|l|}{ Stage } \\
\hline Advanced (III \& IV) & $88(28.8)$ & $82(26.8)$ & 170 & $3.792(2.289-6.282)$ & $<0.001$ & $3.333(1.989-5.585)$ & $<0.001$ \\
\hline Early (I \& II) & $30(9.8)$ & $106(34.6)$ & 136 & & & & \\
\hline \multicolumn{8}{|l|}{ Postoperative status } \\
\hline Suboptimal & $48(15.7)$ & $53(17.3)$ & 101 & $1.747(1.075-2.839)$ & 0.024 & $1.031(0.590-1.802)$ & 0.915 \\
\hline Optimal & $70(22.9)$ & $135(44.1)$ & 205 & & & & \\
\hline \multicolumn{8}{|l|}{ Histology } \\
\hline Serous & 57 (18.6) & $69(22.5)$ & 126 & $1.612(1.010-2.571)$ & 0.045 & $0.816(0.461-1.445)$ & 0.485 \\
\hline Non-serous & $61(19.9)$ & $119(38.9)$ & 180 & & & & \\
\hline \multicolumn{8}{|l|}{ Tumor grade } \\
\hline High grade & $99(32.4)$ & $145(47.4)$ & 244 & $1.545(0.850-2.808)$ & 0.152 & $1.254(0.659-2.386)$ & 0.490 \\
\hline Low grade & $19(6.2)$ & $43(14.1)$ & 62 & & & & \\
\hline \multicolumn{8}{|l|}{ Ascites } \\
\hline Presence & $55(18.0)$ & $61(20.0)$ & 116 & $1.774(1.106-2.846)$ & 0.017 & $0.883(0.484-1.613)$ & 0.687 \\
\hline Absence & $63(20.7)$ & $126(41.3)$ & 189 & & & & \\
\hline
\end{tabular}

OR, odd ratio; Cl, confidence interval; NLR, neutrophil-to-lymphocyte ratio; PLR, platelet-to-lymphocyte ratio; CA125, cancer antigen 125.

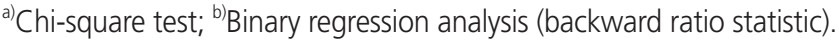




\section{Obstetrics \& Gynecology Science}

Vol. 63, No. 1, 2020

and the presence of ascites showed a poor 5-year overall survival rate in the univariate analysis. However, only a PLR $>210$ and an advanced stage diagnosis were independent potential prognostic factors for survival, with the respective adjusted hazard ratios (HRs) of 1.578 and 3.994. These details are presented in Table 3.

Furthermore, both a high NLR (>3.38) and PLR (>210) were found to be significant in patients with a high CA125 reading ( $\geq 365 \mathrm{IU} / \mathrm{L})$, advanced stage, suboptimal residual tumors and presence of ascites, as noted in Table 4.

\section{Discussion}

The present study found that NLR $>3.38$ and advanced stage were independent predictive factors for platinum resistance. NLR is a very useful parameter in the prediction of chemoresponsiveness due to its ease of determination. This marker could be used to evaluate the systemic balance between neutrophil-dependent pro-tumor inflammation and lymphocyte-associated anti-immune response. High NLR could represent a trend towards increased pro-tumor inflammation

Table 3. Factors related to 5-year overall survival rate

\begin{tabular}{|c|c|c|c|c|c|c|}
\hline \multirow{2}{*}{ Factors } & \multirow{2}{*}{ Total } & \multirow{2}{*}{$\begin{array}{c}\text { 5-year overall } \\
\text { survival rate (\%) }\end{array}$} & \multicolumn{2}{|c|}{ Univariate analysis } & \multicolumn{2}{|c|}{ Cox-Regression analysis ${ }^{\text {a) }}$} \\
\hline & & & $H R^{a)}$ & $P$-value ${ }^{\text {b) }}$ & Adjusted HR & $P$-value \\
\hline \multicolumn{7}{|l|}{ NLR } \\
\hline$>3.38$ & 152 & 34.1 & $1.987(1.421-2.778)$ & $<0.001$ & $1.398(0.958-2.040)$ & 0.083 \\
\hline$\leq 3.38$ & 154 & 61.2 & & & & \\
\hline \multicolumn{7}{|l|}{ PLR } \\
\hline$>210$ & 153 & 33.9 & $2.243(1.599-3.146)$ & $<0.001$ & $1.578(1.045-2.381)$ & 0.030 \\
\hline$\leq 210$ & 153 & 61.0 & & & & \\
\hline \multicolumn{7}{|l|}{ CA125 level (IU/L) } \\
\hline$\geq 365$ & 150 & 36.6 & $1.768(1.270-2.462)$ & 0.001 & $1.225(0.826-1.818)$ & 0.314 \\
\hline$<365$ & 156 & 58.4 & & & & \\
\hline \multicolumn{7}{|l|}{ Parity } \\
\hline Nulliparity & 105 & 55.9 & $1.220(0.860-1.730)$ & 0.210 & $0.960(0.672-1.370)$ & 0.821 \\
\hline Multiparity & 201 & 43.6 & & & & \\
\hline \multicolumn{7}{|l|}{ Stage } \\
\hline Advanced (III \& IV) & 170 & 26.2 & $4.450(2.996-6.611)$ & $<0.001$ & $3.994(2.498-6.384)$ & $<0.001$ \\
\hline Early (I \& II) & 136 & 76.4 & & & & \\
\hline \multicolumn{7}{|l|}{ Postoperative status } \\
\hline Suboptimal & 101 & 32.7 & $1.775(1.271-2.477)$ & 0.001 & $1.283(0.895-1.838)$ & 0.175 \\
\hline Optimal & 205 & 54.8 & & & & \\
\hline \multicolumn{7}{|l|}{ Histology } \\
\hline Serous & 126 & 31.1 & $1.791(1.289-2.490)$ & 0.001 & $1.061(0.722-1.560)$ & 0.761 \\
\hline Non-serous & 180 & 57.8 & & & & \\
\hline \multicolumn{7}{|l|}{ Tumor grade } \\
\hline High grade & 244 & 43.1 & $2.005(1.249-3.217)$ & 0.004 & $1.366(0.837-2.230)$ & 0.212 \\
\hline Low grade & 62 & 66.1 & & & & \\
\hline \multicolumn{7}{|l|}{ Ascites } \\
\hline Presence & 116 & 29.8 & $2.181(1.574-3.024)$ & $<0.001$ & $1.233(0.834-1.825)$ & 0.294 \\
\hline Absence & 189 & 58.9 & & & & \\
\hline
\end{tabular}

HR, hazard ratio; NLR, neutrophil-to-lymphocyte ratio; PLR, platelet-to-lymphocyte ratio; CA125, cancer antigen 125.

${ }^{a}$ Cox proportional hazard model; ${ }^{b)}$ Log rank test. 


\section{Obstetrics \& Gynecology Science}

Dhammapoj Jeerakornpassawat, et al. Potential factors for ovarian cancer

and decreased anti-tumor immune capacity, which might affect the tumor response to chemotherapy $[4,8]$. Miao et al. [9] recently published the role of preoperative NLR and PLR as prognostic markers for predicting the chemotherapeutic response and survival outcomes in 344 EOC patients who received platinum-based chemotherapy. Those authors found that an NLR >3.02 was significant in the prediction of the chemotherapeutic responses. This cutoff point value was similar to the one found in our study. However, the authors also reported significant independent prognostic factors for survival outcomes from both NLR and PLR, whereas in our study, only a high PLR was found to be an independent prognostic factor for poor survival. The cutoff point of PLR in the Miao study [9] was 207, which was similar to the cutoff point of 210 in our study. Both PLR and NLR are promising inflammatory biomarkers of chronic inflammation, which is a key factor in all stages of cancer formation, including initiation, promotion, development and progression of ovarian cancer [10]. Tian et al. [11] recently published a meta-analysis of the prognostic significance of PLR. They performed 11 studies comprising 3,574 patients with EOC and demonstrated that a PLR above 200 revealed a negative impact to both progression-free survival and overall survival. In regards to the NLR, Huang et al. [12] carried out a meta-analysis by recruiting 12 studies, totaling 3,854 EOC patients. They found that a high pre-treatment NLR level was significantly associated with poorer overall survival (HR of 1.69) and shorter progression-free survival (HR of 1.63), as well as a lower chemotherapeutic response (OR, 0.53). The cutoff points of these studies were within a range of 2.11-3.91. The inconsistent outcomes between the present study and previous publications that reported that NLR was significant in platinum resistance but did not affect survival outcomes, whereas the PLR was significant only in the survival outcomes might be due to several reasons. The first is in relation to the differing cutoff points. Our cutoff level was based on the platinum status and not on the survival outcome. Second, the variation in the population may have had an impact, as our study recruited data from fallopian tube cancer and primary peritoneal adenocarcinoma patients, in addition to EOC patients. This was because of the similar treatment guidelines [13]. However, most previous studies recruited only EOC patients, which may have had an impact on the findings [12]. Finally, patients who received initial treatment with neoadjuvant chemotherapy were also enrolled in our study, which again was anomalous to methods used in other studies.

Regarding other predictive factors for chemotherapy resistance, our study found advanced stage was a significant independent factor. To explain this, Li et al. [14] suggested that the mechanism involved in chemotherapeutic resistance

Table 4. Clinical variable divided by neutrophil-to-lymphocyte ratio (NLR) and platelet-to-lymphocyte ratio (PLR)

\begin{tabular}{|c|c|c|c|c|c|c|}
\hline \multirow{2}{*}{ Variables } & \multicolumn{3}{|c|}{ NLR } & \multicolumn{3}{|c|}{ PLR } \\
\hline & $\leq 3.38$ & $>3.38$ & $P$-value ${ }^{\text {a) }}$ & $\leq 210$ & $>210$ & $P$-value ${ }^{\text {a) }}$ \\
\hline CA125 <365 IU/L & $99(32.4)$ & $57(18.6)$ & $<0.001$ & $100(31.7)$ & $56(18.3)$ & $<0.001$ \\
\hline CA125 $\geq 365 \mathrm{IU} / \mathrm{L}$ & $55(18.0)$ & $95(31.0)$ & & $53(17.3)$ & $97(31.7)$ & \\
\hline Early stage (I \& II) & $87(28.4)$ & $49(16.0)$ & $<0.001$ & $88(28.8)$ & $48(15.7)$ & $<0.001$ \\
\hline Advance stage (III \& IV) & $67(21.9)$ & $103(33.7)$ & & $65(21.2)$ & $105(34.3)$ & \\
\hline Optimal residual tumor & $112(36.6)$ & $93(30.4)$ & 0.032 & $112(36.6)$ & $93(30.4)$ & 0.021 \\
\hline Suboptimal residual tumor & $42(13.7)$ & $59(19.3)$ & & $41(13.4)$ & $60(19.6)$ & \\
\hline Non-serous type & $101(33.0)$ & $79(25.8)$ & 0.016 & $94(30.7)$ & $86(28.1)$ & 0.353 \\
\hline Serous type & $53(17.3)$ & $73(23.9)$ & & $59(19.3)$ & $67(21.9)$ & \\
\hline Low grade & $31(10.1)$ & $31(10.1)$ & 0.954 & $28(9.2)$ & $34(11.1)$ & 0.393 \\
\hline High grade & $123(40.2)$ & $121(39.5)$ & & $125(40.8)$ & $119(38.9)$ & \\
\hline No ascites & $108(35.3)$ & $81(26.5)$ & 0.002 & $125(40.8)$ & $64(20.9)$ & $<0.001$ \\
\hline Presence ascites & $46(15.0)$ & $71(23.2)$ & & $28(9.2)$ & $89(29.1)$ & \\
\hline
\end{tabular}

Values are presented as number (\%).

CA125, cancer antigen 125.

${ }^{\text {a) }}$ Chi-square test. 


\section{Obstetrics \& Gynecology Science}

Vol. 63, No. 1, 2020

incorporates the self-renewal and differentiated properties of cancer stem cells, which could be dividing to give rising resistant cells and this mechanism was more common in cancer cells from advanced staged tumors. Due to cancer cells being more resistant to chemotherapy, patients with advanced stage cancers had very poor survival outcomes.

Our study found that high NLR and PLR were more commonly found in patients with high CA125 levels, at an advanced stage, with suboptimal residual tumors, high-grade histology and the presence of ascites. These factors were the main poor prognostic factors for the outcomes of patients with EOC [2].

The strength of our study was the high number of datasets from patients in one institution. This should have decreased the level of variation from blood test laboratory results. However, the very nature of a retrospective study means that some data may be missed, and the precise cause of death reported, and hence the cancer-specific survival outcomes, may not be completely accurate. Thus, greater-designed prospective studies, with adequate numbers of participants that could be controlled for the variable factors, such as neoadjuvant chemotherapy, type of surgery, and type of chemotherapy are needed.

In conclusion, high NLR and advanced stage were potential independent predictive factors for platinum resistance, whereas high PLR and advanced stage were potential independent predictive factors for poor survival outcomes in EOC, fallopian tube cancer, and primary peritoneal adenocarcinoma patients treated with platinum-based chemotherapy. A novel therapy might be beneficial for these patients.

\section{Conflict of interest}

No potential conflict of interest relevant to this article was reported.

\section{Ethical approval}

This retrospective study was conducted following the approval by the Research Ethics Committee at Chiang Mai University Hospital (OBG-2560-05081).

\section{Patient consent}

Informed consent was waived because of the retrospective study design.

\section{References}

1. International Agency for Research on Cancer. Estimated number of new cases in 2018, worldwide, females [Internet]. Lyon: International Agency for Research on Cancer; 2018 [2019 Aug 1]. Available from: http://gco.iarc.fr/today/online-analysistable? $\mathrm{v}=2018 \&$ mode $=$ cancer $\&$ mode_population $=$ conti nents $\&$ population $=900 \&$ populations $=900 \&$ key $=$ asr $\&$ se $\mathrm{x}=2$ \& cancer $=39$ \&type $=0$ \&statistic $=5$ \& prevalence $=0$ \&p opulation_group=0\&ages_group $\% 5 B \% 5 D=10 \& a g e s$ group \% 5B\% 5D=15\&nb_items $=5 \&$ group_ cancer $=1$ \&include_nmsc=1\&include_nmsc_other $=1$.

2. Jayson GC, Kohn EC, Kitchener HC, Ledermann JA. Ovarian cancer. Lancet 2014;384:1376-88.

3. Pignata S, C Cecere S, Du Bois A, Harter P, Heitz F. Treatment of recurrent ovarian cancer. Ann Oncol 2017;28:viii51-6.

4. Ocana A, Nieto-Jiménez C, Pandiella A, Templeton AJ. Neutrophils in cancer: prognostic role and therapeutic strategies. Mol Cancer 2017;16:137-44.

5. Badora-Rybicka A, Nowara E, Starzyczny-Słota D. Neutrophil-to-lymphocyte ratio and platelet-to-lymphocyte ratio before chemotherapy as potential prognostic factors in patients with newly diagnosed epithelial ovarian cancer. ESMO Open 2016;1:e000039.

6. Miao Y, Li S, Yan Q, Li B, Feng Y. Prognostic significance of preoperative prognostic nutritional index in epithelial ovarian cancer patients treated with platinum-based chemotherapy. Oncol Res Treat 2016;39:712-9.

7. Jansaka N, Suprasert P. Survival outcomes of recurrent epithelial ovarian cancer: experience from a Thailand northern tertiary care center. Asian Pac J Cancer Prev 2014;15:10837-40.

8. Moses K, Brandau S. Human neutrophils: their role in cancer and relation to myeloid-derived suppressor cells. Semin Immunol 2016;28:187-96.

9. Miao Y, Yan Q, Li S, Li B, Feng Y. Neutrophil to lymphocyte ratio and platelet to lymphocyte ratio are predictive 


\section{Obstetrics \& Gynecology Science}

Dhammapoj Jeerakornpassawat, et al. Potential factors for ovarian cancer

of chemotherapeutic response and prognosis in epithelial ovarian cancer patients treated with platinum-based chemotherapy. Cancer Biomark 2016;17:33-40.

10. Grivennikov SI, Greten FR, Karin M. Immunity, inflammation, and cancer. Cell 2010;140:883-99.

11. Tian $C$, Song $W$, Tian $X$, Sun $Y$. Prognostic significance of platelet-to-lymphocyte ratio in patients with ovarian cancer: a meta-analysis. Eur J Clin Invest 2018;48:e12917.

12. Huang QT, Zhou L, Zeng WJ, Ma QQ, Wang W, Zhong $M$, et al. Prognostic significance of neutrophil-tolymphocyte ratio in ovarian cancer: a systematic review and meta-analysis of observational studies. Cell Physiol Biochem 2017;41:2411-8.

13. National Comprehensive Cancer Network (US). NCCN clinical practice guidelines in oncology. Fort Washington (PA): National Comprehensive Cancer Network; 2019 [cited 2019 Aug 1]. Available from: https://www.nccn. org/professionals/physician_gls/pdf/ovarian.pdf.

14. Li SS, Ma J, Wong AS. Chemoresistance in ovarian cancer: exploiting cancer stem cell metabolism. J Gynecol Oncol 2018;29:e32. 